\title{
Cell-free fetal DNA in maternal blood - an update of the method and clinical practice
}

\author{
Mona Elena Zvanca, Aida Petca, Mihaela Bot \\ University of Medicine and Pharmacy Carol Davila Bucharest
}

With the event of ultrasound and its introduction into clinical practice, particularly in the field of Obstetrics, a window has opened towards fetal development and a new medical specialty, Fetal Medicine, has emerged. Its development over the past decades is generally superimposed over the technical progress in computer science, biochemistry and lately, genetics and it is shaped by the intervention of ethical, economical and social criteria as well as religious beliefs.

Starting from the obvious desire to see how the fetus is developing, to tackle structural and anatomical abnormalities, to do it as early as possible, the next step was to access fetal information that is beyond visual reach. Diagnosis of chromosomal anomalies and other genetic diseases, as well as fetal metabolic disorders, included sampling of fetal or placental tissues, an invasive manoeuvre that carries a risk to the course of pregnancy. Therefore, alternatives were needed to select those cases in which the necessity overweighs the potential risk. And the first question was: What should we search for? It had to be a pathology that is frequent enough and severe enough to worth investing enormous amounts of finances, human effort and time in order to detect it/them and it had to be curable or, at least preventable. The first to fill these criteria were aneuploidies, particularly trisomy 21 . And fifty years after the first attempts to antenatally diagnose Down syndrome, we are still talking about the same issue.

The history of prenatal screening for aneuploidies starts in the ' 70 s with maternal age over 35 as the sole criteria for selecting a high-risk population of pregnant women. It continues over the next 30 years with the introduction into clinical practice of the second trimester maternal biochemical markers ("triple" and "quad" tests), which doubled the detection rate of trisomy 21 , from previously less than one third (1). Subsequently, the screening policies moved to the first trimester and included ultrasound markers in the form of the "combined test" which, until now represented the standard of care. The ultrasound markers are represented by the measurement of nuchal translucency as a standard and optional measurement, according to local policies, of blood flow through the ductus venosus and across the fetal tricuspid valve and presence of the nasal bone, as established by Fetal Medicine Foundation protocols. The maternal bio-

*Corresponding author: Aida Petca, University of Medicine and Pharmacy Carol Davila Bucharest, ROMANIA; e-mail: aidapetca@gmail.com 
markers include fetal and placental derived proteins: free beta human chorionic gonadotropin (hCG) and pregnancy-associated plasma protein A (PAPP-A). Thus, screening performance has reached about $90 \%$ detection rate for trisomy 21 (2) and $95 \%$ for trisomies 18 and 13 at the cost of a false positive rate of $5 \%(3,4)$. Continuous research had the aim to further increase detection rate, especially for Down syndrome, and reduce the false positive rate. This can be achieved by including into the assessment the entire panel of ultrasound markers and by adding new maternal biomarkers, such as serum placental growth factor (PLGF) and first trimester alpha fetoprotein (AFP) (5). This extended screening algorithm, according to authors, would increase the detection rate of Down syndrome as high as $95 \%$ with a false positive rate of $2 \%$ or even better, by choosing a cut-off risk of $1: 100$. However, there is not sufficient clinical experience with this protocol because of a technological breakthrough, which brought to attention and into routine practice a completely new non-invasive test for fetal genetic disorders: cell-free fetal DNA in maternal plasma.

The first observation was made in 1997 by Dennis Lo who discovered in the plasma of pregnant women fragments of fetal DNA, not attached to any cell structure ("cell-free fetal DNA - cffDNA'), mixed with enormous amounts of maternal DNA (6). The term 'fetal' is not entirely correct, as the main source of pregnancy derived DNA is the placenta. The proportion of fetal DNA compared to maternal DNA is called 'fetal fraction' and it represents one of the main variables, which can influence the accuracy of this test. The size of the DNA fragments is small, around 150 base pairs, but covering the entire human genome. Their half-life is very short (7) and they are undetectable after birth, as this was one of the main difficulties during previous attempts to use fetal DNA from intact fetal cells found in the maternal blood. The basis of the test is to separate maternal from fetal DNA, to sequence molecules of cffDNA from maternal plasma and compare them to the map of the human genome, which is known, in order to see from which chromosome they are derived from. As the size of each chromosome is also known and the proportion between them, the amount of DNA generated by each may be estimated. Variations in these proportions may suggest an alteration in the number of chromosomes. An increase in cffDNA strands derived from chromosome 21 may be an indicative of trisomy 21 , whereas a deficit in cffDNA fragments resulted from chromosome X may suggest monosomy X, for example. First clinical studies, performed on high-risk pregnancies showed that the analysis of cffDNA from maternal blood may be able to detect more than $99 \%$ of cases with trisomy 21 at the cost of a false positive rate of less than $1 \%$ (8-10). The performance of the test is directly related to the fetal fraction.

In maternal plasma cffDNA may be detected starting from 4 weeks of pregnancy and rises continuously. The fetal fraction reaches about $4 \%$ in most cases at 10 weeks, which is considered a minimal requirement for the detection of a chromosomal numerical aberration (11). The fetal fraction is significantly lower in overweight mothers and is increased in cases with high levels of free beta-hCG and PAPP-A. It is not significantly related to maternal age, storage time, smoking status, nuchal translucency thickness, fetal crown-rump length, gender or karyotype (12). In his study Nicolaides $\mathrm{KH}$ et al. found that the fetal fraction declines from a mean of about $12 \%$ at a $60 \mathrm{~kg}$ maternal weight to as low as $6 \%$ at $120 \mathrm{~kg}$. This inverse relationship may be attributed to a dilution effect and is similar to PAPP-A dynamics. On the other hand, there are suspicions that the fetal fraction may vary with other pregnancy complications, such as preeclampsia and preterm birth and it may serve as 
a marker for these pathologies, but so far, this is considered an overstatement.

The clinical test is conventionally named Non Invasive Prenatal Testing (NIPT), with different commercial labels. The ambiguity of the name reflects exactly the lack of sufficient clinical evidence to whether this test is a screening test or a diagnostic tool. So far it has been agreed that we are still dealing with a screening test, the best yet, and it is incorporated as such in different protocols.

Different companies developed different techniques to separate maternal from fetal DNA and to sequence the latter. Thus, three main types of NIPT analysis emerged.

\section{Shotgun Massively Parallel Sequencing (S-MPS)}

The approach relies on identifying and sequencing all plasmatic DNA fragments, both maternal and fetal. All informative regions are taken into account and because chromosome 21 is small, representing about $1.5 \%$ of the human genome, the technique sequences many millions of DNA molecules from the entire genome in order to ensure sufficient amount of chromosome 21 for analysis. The cost of the method is high, but it has a high performance, with a low rate of non-informative results (2\%) (13). Recently, there are publications about the possibility of detecting microdeletions, particularly the most common 22q (di George syndrome).

\section{Targeted Massively Parallel Sequencing (t-MPS) or Chromosome- Selective Sequence Analysis (CSS)}

In order to reduce costs some companies have developed a technique that is selecting for sequencing only DNA fragments specific to chromosomes 21, 13, 18, X and Y. The disadvantage of this method is that it requires higher fetal fractions in order to obtain a result and it fails to provide results in $2-4 \%$.

\section{Single Nucleotid Polymorphism (SNP) technique}

The basis of this test relies on the DNA polymorphism, variations that are associated with individual traits. On the same chromosome, in the same locus, the fetus has different SNPs than the mother, which allows the distinction between the DNA fragments from maternal plasma. Moreover, this technique does not require a witness sample. The same sample of maternal plasma, after separation, becomes the source of maternal DNA (buffy coat) and maternal and fetal DNA (the superficial layer). Multiplex PCR is used to quantify around 20,000 polymorphic loci on chromosomes 21, 13, 18 and sex chromosomes and the detected differences undergo complex mathematical calculations (14). The test is more sensitive to low fetal fractions and the rate of non-informative results is $3-5 \%$. The SNP method may identify triploidy and establish zigosity in twin pregnancies. There are ongoing clinical trials for the detection of microdeletions/ microduplications.

When comparing the results of clinical studies, it is necessary to stress out that initial data emerged from high-risk pregnancies. Unlike conventional, combined screening, where detection rates for trisomy 21 were generally lower than for trisomy 13 and 18, and karyotyping, where there is uniform diagnosis of aneuploidies, NIPT provides far better prediction for Down syndrome, with a detection rate which varies from $98.6 \%$ (9) to $100 \%(15-17)$, for a false positive rate of $0.16 \%$. For Edwards syndrome the overall detection rate is around 97\%, with a false positive rate of $0.15 \%$ and for Patau syndrome it is the lowest, $92 \%$, with $0.2 \%$ false positive rate (18). 
Subsequent studies in low risk population proved that NIPT is as effective in detecting anomalies of chromosomes 21, 13, 18, $\mathrm{X}$ and $\mathrm{Y}$ $(19,20)$.

\section{Twin pregnancies}

The main technical difficulty in a twin pregnancy is that in the maternal blood there is a combination of DNA from the mother and two fetuses, dizygotic or monozygotic, which may involve two placentas or one placenta. If the pregnancy is dizygotic and one of the fetuses is trisomic, the excessive amount of a certain chromosome may be masked, diluted, by the normal amount of the same chromosome from the other fetus. Moreover, each fetus can contribute with different amounts of cffDNA and the differences may be very important $(21,22)$. However, taking into account the lower fetal fraction of the two, Gil MM et al. found that results may be provided in about $93 \%$ of cases (23), which is unacceptably low.

Screening for aneuploidies in multiple pregnancies is an important issue. Firstly, because the number of multiple pregnancies has increased rapidly in the past decade due to the widespread of assisted reproductive technologies. Secondly, the mean maternal age in twin pregnancies is higher and, therefore, the rate of screen-positive results using combined screening is higher. If invasive testing for karyotyping is considered, the risk of miscarriage is also higher. So far, NIPT studies in twin pregnancies enrolled a small number of cases, but the reasonable conclusion is that the first line of screening should be the conventional one: detailed 11 - 14 weeks ultrasound, maternal serum biomarkers and cffDNA as a contingent screening for intermediate/highrisk pregnancies.

\section{Introduction of NIPT into clinical practice}

As previously stated, NIPT is the best screening tool for aneuploidies and it may be a logical step to replace other screening techniques. According to Nicolaides et al. (24) if cffDNA was offered as a first line method of screening to all pregnancies, almost $99 \%$ of fetuses with trisomy 21 would be detected and $96 \%$ of those with trisomies 13 and 18, for an invasive testing rate of $1 \%$. However, these results are based on a series of assumptions, especially related to the performance of the test in a low-risk population and to the failure rate. In fetuses with structural abnormalities or increased NT measurement it is not reasonable to limit genetic investigations to chromosomes 21, 13, 18, X, Y. But in order to detect these fetuses, a prior detailed ultrasound is required for all pregnancies.

Therefore, the recommendations are to use cffDNA as a contingent testing based on the results of $11-14$ weeks combined screening, thus retaining the advantages of early detection of fetal structural abnormalities. In these conditions NIPT may be offered to structurally normal fetuses with intermediate risk. Also, this strategy significantly reduces the screening costs.

\section{Romanian reality and perspective}

The underfinance and the lack of a generally accepted and updated protocol for pregnancy care, result in a chaotic screening process. However, there are encouraging results in urban population, but these are related mainly to the higher degree of education and better financial resources of the pregnant women and less to a consistent screening strategy.

Personal experience in a Bucharest hospital and a private genetic laboratory indicate a very prompt positive reaction of the patients at 
the clinical availability of NIPT. Even considering the increased cost, the demand for cffDNA testing in selected intermediate risk population versus invasive karyotyping was very high. Between January - June 2013 NIPT was performed in our laboratory for 52 singleton pregnancies. Between January - June 2014 the number of requests increased to 104 . This may be the result of better marketing as well as of a reduction in price. Both S-MPS and SNP technologies were used with an overall failure to obtain results from the first blood draw of about 3\%. There were no false negative results so far.

Clinicians have already grasped the enormous potential as a research area of NIPT and there are a number of original scientific articles, some remarkable through the innovative technologies used to differentiate maternal and fetal DNA (25). Even though the number of cases is small, a mixed team of obstetricians, geneticists and laboratory doctors from 3 major Romanian universities carried out this study and is the first of this kind in Romania.

\section{Conclusions}

Are we looking into the face of future? Probably so, but the technology still needs improvement. Until the moment when it can replace karyotyping, either cytogenetic or molecular, it has to be able to provide at least the same information: chromosome number, for all chromosomes, chromosome structure, submicroscopic chromosomal anomalies, with a sensitivity as high as $100 \%$. Also, the method has to be proven effective in singleton, as well as in multiple pregnancies, in high-risk fetuses, in those with structural anomalies, as well as in low risk pregnancies. In addition, the cost needs to be low enough as to consider implementing NIPT as a test for all pregnancies, after the $11-14$ weeks ultrasound.

\section{References}

1. Benn P, Cuckle H, Pergament E. Non-invasive prenatal testing for aneuploidy: current status and future prospects. Ultrasound Obstet Gynecol. 2013;42(1):5-33. DOI: $10.1002 /$ uog. 12513

2. Cuckle H, Benn P. Multianalyte maternal serum screening for chromosomal defects. In Genetic Disorders and the Fetus: Diagnosis, Prevention and Treatment (6th Edn), Milunsky A, Milunsky JM (eds). Wiley-Blackwell, Chichester, UK. 2010;771-818.

3. Nicolaides KH. Screening for fetal aneuploidies at 11 to 13 weeks. Prenat Diagn. 2011;31(1):7-15. DOI: 10.1002/pd.2637

4. Kagan KO, Wright D, Valencia C, Maiz N, Nicolaides KH. Screening for trisomies 21, 18 and 13 by maternal age, fetal nuchal translucency, fetal heart rate, free $\beta$-hCG and pregnancy-associated plasma protein-A. Hum Reprod. 2008;23(9):1968-1975. DOI: 10.1093/ humrep/den 224

5. Wright D, Syngelaki A, Bradburi I, Akolekar R, Nicolaides KH. First-trimester screening for trisomies 21, 18 and 13 by ultrasound and bio-chemical testing. Fetal Diagn Ther. 2014; in press. DOI: 10.1159/000357430

6. Lo YMD, Corbetta N, Chamberlain PF, Rai V, Sargent IL, Redman CWG, et al. Presence of fetal DNA in maternal plasma and serum. Lancet. 1997;350(9076):4857. DOI: 10.1016/S0140-6736(97)02174-0

7. Lo YMD, Zhang J, Leung TN, Lau TK, Chang AM, Hjelm NM. Rapid clearance of fetal DNA from maternal plasma. Am J Hum Genet. 1999;64(1):218-24. DOI: $10.1086 / 302205$

8. Chiu RW, Akolekar R, Zheng YW, Leung TY, Sun $\mathrm{H}$, Chan $\mathrm{KC}$, et al. Non-invasive pre- natal assessment of trisomy 21 by multiplexed maternal plasma DNA sequencing: large scale validity study. BMJ. 2011;342:c7401. DOI: 10.1136/bmj.c7401

9. Palomaki GE, Kloza EM, Lambert-Messerlian GM, Haddow JE, Neveux LM, Ehrich M, et al. DNA sequencing of maternal plasma to detect Down syndrome: an international clinical validation study. Genet Med. 2011;13(11):913-20. DOI: 10.1097/GIM.0b013e$3182368 \mathrm{a} 0 \mathrm{e}$

10. Sparks AB, Struble CA, Wang ET, Song K, Oliphant A. Noninvasive prenatal detection and selective analysis of cell-free DNA obtained from maternal blood: evaluation for trisomy 21 and trisomy 18 . Am J Obstet Gynecol. 2012;206(4):319.e1-9. DOI: 10.1016/j. ajog.2012.01.030

11. Ehrich M, Deciu C, Zwiefelhofer T, Tynan JA, Cagasan L, Tim R, et al. Noninvasive detection of fetal trisomy 21 by sequencing of DNA in maternal blood: a study in a clinical setting. Am J Obstet Gynecol. 2011;204(3):205. e1-11. DOI: 10.1016/j.ajog.2010.12.060

12. Ashoor G, Poon L, Syngelaki A, Mosimann B, Nico- 
laides KH. Fetal Fraction in Maternal Plasma Cell-Free DNA at 11-13 Weeks' Gestation: Effect of Maternal and Fetal Factors. Fetal Diagn Ther. 2012;31(4):23743. DOI: $10.1159 / 000337373$

13. Sehnert AJ, Rhees B, Comstock D, Comstock D, de Feo E, Heilek G, et al. Optimal detection of fetal chromosomal abnormalities by massively parallel DNA sequencing of cell-free fetal DNA from maternal blood. Clin Chem. 2011;57(7): 1042-9. DOI: 10.1373/ clinchem.2011.165910

14. Zimmermann B, Hill M, Gemelos G, Demko Z, Banjevic M, Baner J, et al. Noninvasive prenatal aneuploidy testing of chromosomes $13,18,21, \mathrm{X}$, and Y, using targeted sequencing of polymorphic loci. Prenat Diagn. 2012;32(13):1233-41. DOI: 10.1002/pd.3993

15. Ashoor G, Syngelaki A, Wagner M, Birdir C, Nicolaides $\mathrm{KH}$. Chromosome-selective sequencing of maternal plasma cell-free DNA for first-trimester detection of trisomy 21 and trisomy. Am J Obstet Gynecol. 2012;206(4):322.e1-5. DOI: 10.1016/j. ajog.2012.01.029

16. Norton ME, Brar H, Weiss J, Karimi A, Laurent LC, Caughey AB, et al. Non-Invasive Chromosomal Evaluation (NICE) Study: results of a multicenter prospective cohort study for detection of fetal trisomy 21 and trisomy 18. Am J Obstet Gynecol. 2012; 207(2):137. e1-8. DOI: 10.1016/j.ajog.2012.05.021

17. Palomaki GE, Deciu C, Kloza EM, Lambert-Messerlian GM, Haddow JE, Neveux LM, et al. DNA sequencing of maternal plasma reliably identifies trisomy 18 and trisomy 13 as well as Down syndrome: an international collaborative study. Genet Med. 2012;14(3):296-305. DOI: $10.1038 /$ gim.2011.73

18. Gll MM, Akolekar R, Quezada MS, Bregant B, Nicolaides KH. Analysis of cell-free DNA in maternal blood in screening for aneuploidies: meta-analysis. Fetal Diagn Ther. 2014;35(3):156-173. DOI:
$10.1159 / 000358326$

19. Dan S, Wang W, Ren J, Li Y, Hu H, Xu Z, et al. Clinical application of massively parallel sequencing-based prenatal noninvasive fetal trisomy test for trisomies 21 and 18 in 11,105 pregnancies with mixed risk factors. Prenat Diagn. 2012;32(13):1225-32. DOI: 10.1002/ pd.4002

20. Lau TK, Chan MK, Salome Lo PS, Chan HY, Chan WS, et al. Clinical utility of noninvasive fetal trisomy (NIFTY) test-early experience. J Matern Fetal Neonatal Med. 2012;25(10):1856-9. DOI: 10.3109/14767058.2012.678442

21. Qu JZ, Leung TY, Jiang P, Liao GJ, Cheng YK, Sun $H$, et al. Noninvasive prenatal determination of twin zygosity by maternal plasma DNA analysis. Clin Chem. 2013;59(2):427-35. DOI: 10.1373/ clinchem.2012.194068

22. Leung TY, Qu JZ, Liao GJ, Jiang P, Cheng YK, Chan $\mathrm{KC}$, et al. Noninvasive twin zygosity assessment and aneuploidy detection by maternal plasma DNA sequencing. Prenat Diagn. 2013;33(7):675-81. DOI: $10.1002 / \mathrm{pd} .4132$

23. Gil MM, Quezada MS, Bregant B, Syngelaki A, Nicolaides KH. Cell-Free DNA Analysis for Trisomy Risk Assessment in First-Trimester Twin Pregnancies. Fetal Diagn Ther. 2014;35(3):204-11. DOI: $10.1159 / 000356495$

24. Nicolaides KH, Syngelaki A, Poon LC, Gil MM, Wright D. First Trimester Contingent Screeningfor Trisomies 21, 18 and 13 by Biomarkers and Maternal Blood CellFree DNA Testing. Fetal Diagn Ther. 2014;35(3):18592. DOI: $10.1159 / 000356066$

25. Gorduza EV, Popescu R, Caba L, Ivanov I, Martiniuc V, et al. Prenatal diagnosis of 21 trisomy by quantification of methylated fetal DNA in maternal blood: study on 10 pregnancies. Rev Romana Med Lab. 2013;21(3):27584. DOI: $10.2478 / \mathrm{rrlm}-2013-0030$ 